\title{
Demographic and Health-related Risk Factors of Subclinical Vitamin A Deficiency in Ethiopia
}

\author{
Tsegaye Demissie', Ahmed Ali², Yared Mekonnen³, Jemal Haider', and Melaku Umeta' \\ 'Ethiopian Health and Nutrition Research Institute, PO Box 5654, Addis Ababa, Ethiopia, ${ }^{2}$ Community Health Department, Addis Ababa \\ University, PO Box 9086, and 3Mella Population, Health and Nutrition Consultancy Service, PO Box 34422, Addis Ababa, Ethiopia
}

\begin{abstract}
The study was conducted to determine the demographic and health-related risk factors of subclinical vitamin A deficiency in Ethiopia. Blood samples were collected from 996 children in 210 clusters across the nation for analysis of serum retinol. Interviews were conducted with the respective mothers of the 996 children on presumed risk factors of vitamin A deficiency. A higher subclinical vitamin A deficiency was associated with: not receiving vitamin A supplement over the year, having been ill during the two weeks preceding the survey, no or incomplete vaccination, belonging to a mother with high parity, and low levels of awareness of vitamin A. Moreover, being from Muslim household was strongly associated with higher levels of subclinical vitamin A deficiency. Among the risk factors identified, low levels of vaccination, high parity, and low levels of maternal awareness of vitamin A contributed to higher risks of vitamin A deficiency among Muslim children. The findings underscore the need for creation of strengthened awareness of family planning and importance of vitamin A, promotion of vaccination and child health, intensification of vitamin A supplementation, and in-depth investigation on factors contributing to increased vulnerability of Muslim children.
\end{abstract}

Key words: Cross-sectional studies; Risk factors; Serum retinol; Vitamin A; Vitamin A deficiency; Xerophthalmia; Ethiopia

\section{INTRODUCTION}

The far-reaching health consequence of vitamin A deficiency is well-substantiated by numerous welldesigned scientific studies $(1,2)$. Meta-analysis of a number of trials has clearly demonstrated that as much as $23 \%$ reduction in mortality of children could be achieved by improving vitamin A status (3). Several studies have established that vitamin A deficiency is a major public-health problem in Ethiopia (4-10). Except in the southern region where studies have consistently shown low levels of vitamin A deficiency $(4,10)$, the problem has continued to constitute a major public-health concern in other regions. In some regions, close to $8 \%$ prevalence rate of Bitot's spot (clinical vitamin A deficiency) was reported, perhaps the highest rate ever recorded in the world (6). The

Correspondence and reprint requests should be addressed to:

Dr. Tsegaye Demissie

Ethiopian Health and Nutrition Research Institute PO Box 5654

Addis Ababa, Ethiopia

Email: tsg@ethionet.et

Fax: 251-11-2752533 fifth nutrition situation report of the Standing Committee on Nutrition of the United Nations indicates that the prevalence of xerophthalmia in Ethiopia is the highest in the world (11).

Cognizant of the wide-scale prevalence and enormous health impacts, interventions were initiated as early as in 1960 in Ethiopia. During 1969-1973, a pilot intervention study in two towns-one with nutrition education and the other with vitamin A capsule distribution-emphasized the value of these interventions, and following this, diseasetargeted vitamin A supplementation, along with nutrition education, was initiated. The nationwide vitamin A supplementation began in 1995 as a component of Expanded Programme on Immunization (EPI), and starting from 1997, vitamin A supplementation was effected through campaigns either integrated with the National Immunization Days or as a stand-alone activity. Initially, the coverage was good but later the coverage dropped substantially as a result of deaths occurring during the supplementation. While squeezing the contents of the capsule during oral dosing, in some rare instances, the entire capsules slipped into the mouth 
of children and choked them by sticking to esophagus and blocking air passage. At the time of this survey, an enhanced outreach strategy, incorporating deworming and other health interventions, along with vitamin A supplementation, was being implemented in three regions.

The primary cause of vitamin A deficiency is inadequate dietary consumption of vitamin A and/ or suboptimal use of the nutrient in the body. A number of secondary factors contribute to insufficient dietary intake of vitamin A. Inadequate production of vitamin A-rich foods, lack of income to purchase, unavailability of vitamin A-rich foods in markets, a large family size, high maternal parity levels, low level of maternal education, low levels of awareness of the importance of vitamin A, and illness are some secondary factors that are presumed to contribute to inadequate consumption of vitamin A in developing countries.

As the risk factors and determinants of vitamin A are context-specific (socioeconomic, cultural, environmental, etc.), variations in factors contributing to vitamin A deficiency exist among countries, regions, and localities, underlining the need to assess country/region/area-specific risk factors. Knowledge on such specific risk factors enables implementers and policy-makers to design and implement effective interventions. Unfortunately, studies relating to country and region or area-specific causes of vitamin A in Ethiopia are scarce, and hence, substantive information regarding factors contributing to vitamin A deficiency is lacking. The aim of this study was to partially fill the information gap on causes of vitamin A deficiency by providing information on some demographic and health-related risk factors.

\section{MATERIALS AND METHODS}

\section{Survey design and sampling}

Multi-stage, cluster-sampling approach and crosssectional design were employed in the study. Nine of the 11 regional administrative states that constitute the Federal Government of Ethiopia were included in the survey (two regions were excluded due to security reasons). In each region, 30 clusters (villages) were randomly selected, and blood samples were collected from five systematically-selected children, bringing the regional sample size to 150 children and the national sample size to 1,350 children (nine regions). The sample size of 150 children per region was determined based on $44 \%$ prevalence rate of deficient serum retinol levels reported in the 1980/1981 national study that is $\mathrm{p}=44 \%$, confidence interval $=95 \%$, worst acceptable $=54 \%$, and clustering effect of 2 . Interviews pertaining to household, maternal and child characteristics presumed to contribute to vitamin A deficiency were conducted with mothers of the children included in biochemical assessment. In the final analysis, the serum retinol results of the 996 children (due to insufficient blood for analysis) and corresponding maternal interviews were used.

\section{Collection of data}

Laboratory technicians trained by experienced senior laboratory technicians collected blood samples. All necessary safety measures were strictly maintained during blood collection. Blood samples were kept in an icebox and in a dark place until they were transported to health institutions where centrifuges and refrigerators were available. After centrifuging, the sera were kept in a deep freezer at $-80^{\circ} \mathrm{C}$. Analysis of serum retinol was performed at the Ethiopian Health and Nutrition Research Institute, Addis Ababa, using high-performance liquid chromatography (12).

Ethical approval was obtained from the Research and Ethical Clearance Committee at the National Health and Nutrition Research Institute. Following thorough explanations about the importance of the survey, consents from families were requested. Blood collection ensued only when the consent of the family was obtained. At the end of collection of blood samples, biscuits and soaps were given to children as incentives.

Trained data collectors administered the household questionnaire. A three-day thorough theoretical and practical training was given to the data collectors. Data collection commenced only when common understanding among all the data collectors was reached.

\section{Processing and analysis of data}

Age of the children was categorized as 6-24 months, 25-48 months, and 49-72 months. Age of the mothers was categorized as below 25 years, 25-35 years, and above 35 years. The education level of mothers was categorized as 'illiterate' when the mother could not read/write and 'literate' when the mother could read/write or has gone to formal school. The overall knowledge of the mothers regarding vitamin A refers to knowing or not knowing at least one aspect of vitamin A (consequences, foods rich in vitamin A, or the importance). Similarly, overall 
illness refers to being ill over 15 days preceding the survey, regardless of types, episode, and the severity of illness. The World Health organization recommends serum retinol levels of $<0.7 \mu$ mole/L as a cut-off point, indicative of the presence of subclinical vitamin A deficiency (13). This cut-off point was used in this study.

Serum retinol results and data collected through interviews were entered into computer using the SPSS software (version 13.0), and analysis was done in the same software. Bivariate logistic regression was used for examining the strength of the association of each variable to vitamin A (without controlling for the effect of other variables). Multivariate logistic regression was used for examining the independent, collective and individual contributions of child, maternal and household attributes. Three models were constructed. The first model contained only child characteristics; the second model contained child and maternal characteristics; and the third one (full model) contained child, maternal and household characteristics.

\section{RESULTS}

Table 1 shows the prevalence of subclinical vitamin A deficiency by child-related risk factors. The results of bivariate analysis indicated that the prevalence of subclinical vitamin A deficiency was not markedly different between female and male children.
Neither significant difference nor discernable trend in subclinical vitamin A deficiency was observed among children in the three age-categories. However, the rate of prevalence of subclinical vitamin A deficiency was significantly higher among children who did not complete vaccination compared to those who had completed, among children who were ill in the 15 days prior to the survey compared to those who were not, and among those who did not receive vitamin A supplement at least once over the year compared to those who had received.

The prevalence of subclinical vitamin A deficiency by household and maternal characteristics is shown in Table 2 . The bivariate results showed lack of significant difference in the prevalence of subclinical vitamin A deficiency among rural and urban children. The prevalence of subclinical vitamin A deficiency was modestly but significantly higher among children belonging to large-sized households (six and more members) and more underfive siblings (two or more) compared to children belonging to small-sized households (five and less) and a few under-five siblings (one or none). The prevalence of subclinical vitamin A deficiency was significantly higher among Muslim children than among Christian children.

There was no difference in the prevalence of subclinical vitamin A deficiency among children

\begin{tabular}{|c|c|c|c|c|c|}
\hline \multirow{2}{*}{ Variable } & \multicolumn{2}{|c|}{ No. of children } & \multicolumn{2}{|c|}{ Deficient } & \multirow{2}{*}{$\begin{array}{l}\text { Unadjusted OR } \\
\quad(95 \% \mathrm{CI})\end{array}$} \\
\hline & No. & $\%$ & No. & $\%$ & \\
\hline \multicolumn{6}{|l|}{$\operatorname{Sex}(n=962)$} \\
\hline Female & 465 & 48.3 & 156 & 33.5 & \multirow{2}{*}{$1.06(0.10-1.38)$} \\
\hline Male & 497 & 51.7 & 173 & 34.8 & \\
\hline \multicolumn{6}{|l|}{ Age (months) $(\mathrm{n}=960)$} \\
\hline 24 and below & 192 & 19.9 & 65 & 33.9 & \multirow{3}{*}{$1.03(0.86-1.23)$} \\
\hline $25-48$ & 376 & 39.0 & 128 & 34.0 & \\
\hline $49-72$ & 397 & 41.1 & 139 & 35.0 & \\
\hline \multicolumn{6}{|l|}{ Vaccination status $(\mathrm{n}=966)$} \\
\hline Not at all/incomplete & 468 & 48.4 & 184 & 39.3 & \multirow{2}{*}{$1.53(1.17-2.00)$} \\
\hline Complete & 498 & 51.6 & 148 & 29.7 & \\
\hline \multicolumn{6}{|c|}{$\begin{array}{l}\text { Vitamin A supplementation } \\
\text { last year }\end{array}$} \\
\hline Received at least once & 369 & 38.2 & 104 & 28.2 & \multirow{2}{*}{$1.57(1.19-2.08$} \\
\hline Not at all received & 597 & 61.8 & 228 & 38.2 & \\
\hline \multicolumn{6}{|l|}{ Overall illness $(\mathrm{n}=955)$} \\
\hline None & 513 & 53.1 & 160 & 31.2 & \multirow{2}{*}{$1.35(1.04-1.76)$} \\
\hline At least one illness & 453 & 46.9 & 172 & 38.0 & \\
\hline
\end{tabular}




\begin{tabular}{|c|c|c|c|c|c|}
\hline \multirow{2}{*}{ Variable } & \multicolumn{2}{|c|}{ No. of children } & \multicolumn{2}{|c|}{ Deficient } & \multirow{2}{*}{$\begin{array}{l}\text { Unadjusted OR } \\
(95 \% \mathrm{CI})\end{array}$} \\
\hline & No. & $\%$ & No. & $\%$ & \\
\hline \multicolumn{6}{|l|}{ Residence (n=966) } \\
\hline Rural & 631 & 65.3 & 207 & 32.8 & \multirow{2}{*}{$0.82(0.62-1.08)$} \\
\hline Urban & 335 & 34.7 & 125 & 37.3 & \\
\hline \multicolumn{6}{|l|}{ Religion (n=949) } \\
\hline Christian & 581 & 60.1 & 149 & 25.6 & \multirow{2}{*}{$2.63(2.00-3.45)$} \\
\hline Muslim & 385 & 39.9 & 183 & 47.5 & \\
\hline \multicolumn{6}{|c|}{ Household size $(\mathrm{n}=965)$} \\
\hline 5 and below & 559 & 57.9 & 177 & 31.7 & \multirow{2}{*}{$1.33(1.02-1.74)$} \\
\hline 6 and above & 406 & 42.1 & 155 & 38.2 & \\
\hline \multicolumn{6}{|c|}{ No. of under-five children ( $n=966)$} \\
\hline 1 or none & 500 & 51.8 & 152 & 30.4 & \multirow{2}{*}{$1.44(1.10-1.88)$} \\
\hline 2 and above & 466 & 48.2 & 180 & 38.6 & \\
\hline \multicolumn{6}{|c|}{ Literacy status of mothers $(\mathrm{n}=966)$} \\
\hline Illiterate & 588 & 60.9 & 220 & 37.4 & \multirow{2}{*}{$1.42(1.08-1.87)$} \\
\hline Literate & 378 & 39.9 & 112 & 29.6 & \\
\hline \multicolumn{6}{|l|}{ Parity (n=957) } \\
\hline 2 and below & 407 & 41.1 & 119 & 29.2 & \multirow{2}{*}{$1.49(1.13-1.96)$} \\
\hline 3 and above & 559 & 57.9 & 213 & 38.1 & \\
\hline \multicolumn{6}{|c|}{ Knowledge about vitamin A $(\mathrm{n}=960)$} \\
\hline Not at all & 761 & 78.8 & 284 & 37.3 & \multirow{2}{*}{$1.95(1.36-2.78)$} \\
\hline At least one fact & 205 & 21.2 & 48 & 23.4 & \\
\hline \multicolumn{6}{|c|}{ Age (years) of mothers $(n=960)$} \\
\hline 24 or below & 246 & 25.6 & 89 & 36.2 & \multirow{3}{*}{$0.94(0.75-1.17)$} \\
\hline $25-35$ & 587 & 61.1 & 198 & 33.7 & \\
\hline Above 35 & 127 & 13.2 & 43 & 33.9 & \\
\hline
\end{tabular}

born to older, middle-age and younger mothers. However, the prevalence was significantly higher among children whose mothers had more deliveries (three and above), children belonging to illiterate mothers, and children belonging to mothers who had low levels of awareness of vitamin A compared to children whose mothers had a few deliveries (two and below), children belonging to literate mothers, and children belonging to mothers who had better awareness of vitamin $\mathrm{A}$.

The results of multivariate logistic analysis are presented in Table 3. Among the child attributes (model I), not receiving vitamin A supplements at least once over the year (odds ratio $[\mathrm{OR}]=1.74$; 95\% confidence interval [CI] 1.30-2.35), illness over two weeks prior to the survey $(\mathrm{OR}=1.40 ; 95 \%$ CI 1.06-1.83), and incompletion of vaccination $(\mathrm{OR}=1.43 ; 95 \%$ CI 1.10-1.99) were significantly as- sociated with high levels of subclinical vitamin A deficiency. Among the combined child and maternal variables (model II), the child attributes that were significant in model I and high parity levels $(\mathrm{OR}=1.70$; 95\% CI 1.23-2.32) and lack of awareness about vitamin A (OR=1.80; 95\% CI 1.24-2.64) from the maternal attributes were significantly associated with high levels of subclinical vitamin A deficiency. While all the maternal and child-related attributes that were significant in Model II persisted to be significantly associated (model III), only religion was strongly and significantly $(\mathrm{OR}=2.23 ; 95 \%$ CI 1.63-3.06) associated with subclinical vitamin A deficiency from the household characteristics.

The likelihood ratio associated with the full model (model III) was 80.94 ( $\mathrm{p}=0.000)$. Of this total likelihood ratio, child-related attributes (vitamin A supplementation, illness, and vaccination status) contributed only 19.39 (23.96\%), maternal char- 
Table 3. Risk factors contributing to vitamin A deficiency in Ethiopia; adjusted OR (95\% CI)

\begin{tabular}{|c|c|c|c|c|}
\hline Variable & No. & Model I & Model II & Model III \\
\hline $\begin{array}{l}\text { Religion } \\
\text { Christian } \\
\text { Muslim }\end{array}$ & $\begin{array}{l}581 \\
385\end{array}$ & -- & -- & $\begin{array}{c}1 \\
2.23(1.63-3.06)\end{array}$ \\
\hline $\begin{array}{l}\text { Residence } \\
\text { Urban } \\
\text { Rural }\end{array}$ & $\begin{array}{l}335 \\
631\end{array}$ & -- & -- & $\begin{array}{c}1 \\
0.82(0.60-1.14)\end{array}$ \\
\hline $\begin{array}{l}\text { Family size } \\
\quad \leq 5 \text { (small) } \\
\quad \geq 6 \text { (large) }\end{array}$ & $\begin{array}{l}559 \\
406\end{array}$ & -- & -- & $\begin{array}{c}1 \\
1.08(0.78-1.53)\end{array}$ \\
\hline $\begin{array}{l}\text { No. of }<5 \text { children } \\
\quad<2 \\
\quad \geq 2\end{array}$ & $\begin{array}{l}500 \\
466\end{array}$ & -- & -- & $\begin{array}{c}1 \\
1.15(0.85-1.55)\end{array}$ \\
\hline $\begin{array}{l}\text { Maternal age (years) } \\
\quad \leq 24 \\
25-\leq 35 \\
>35\end{array}$ & $\begin{array}{l}246 \\
587 \\
127\end{array}$ & -- & $\begin{array}{c}1 \\
0.75(0.53-1.06) \\
0.60(0.36-1.18)\end{array}$ & $\begin{array}{c}1 \\
0.80(0.60-1.14) \\
0.72(0.43-1.22)\end{array}$ \\
\hline $\begin{array}{l}\text { Maternal literacy } \\
\text { literate } \\
\text { Illiterate }\end{array}$ & $\begin{array}{l}378 \\
588\end{array}$ & -- & $\begin{array}{c}1 \\
1.10(0.81-1.50)\end{array}$ & $\begin{array}{c}1 \\
0.91(0.66-1.30)\end{array}$ \\
\hline $\begin{array}{l}\text { Parity } \\
\leq 2 \text { births } \\
\geq 3 \text { births }\end{array}$ & $\begin{array}{l}407 \\
559\end{array}$ & -- & $\begin{array}{c}1 \\
1.70(1.23-2.32)\end{array}$ & $\begin{array}{c}1 \\
1.46(1.02-2.09)\end{array}$ \\
\hline $\begin{array}{l}\text { Knowledge about vitamin A } \\
\text { At least one fact } \\
\text { None }\end{array}$ & $\begin{array}{l}205 \\
761\end{array}$ & -- & $1.80(1.24-2.64)$ & $1.80(1.22-2.70)$ \\
\hline
\end{tabular}

Age (months) of children

$\leq 24$

$25-\leq 48$

$\geq 49-71$

192

376

397

1

$1.05(0.72-1.53)$

$1.07(0.73-1.55)$

$1.05(0.71-1.54)$

$0.99(0.68-1.46)$

1

$1.12(0.76-1.66)$

$1.13(0.76-1.68)$

Sex

Female

465

Male

497

1

$1.10(0.84-1.44)$

1

1

$1.11(0.84-1.50)$

$1.10(0.83-1.46)$

Vaccination status

Complete

498

468

1

1

1

No/incomplete

$1.74(1.30-2.35)$

$1.80(1.32-2.43)$

$1.54(1.12-2.12)$

Illness

Not at all ill

Ill at least once

513

453

1

$1.40(1.06-1.83)$

1

1

$1.40(1.05-1.82)$

$1.42(1.07-1.90)$

Vitamin A supplementation Received

Not received

369

597

1

1

$1.43(1.10-1.99) \quad 1.46(1.02-2.03)$

1

$1.45(1.12-2.31)$

$45.94(\mathrm{p}=0.000)$

$80.94(\mathrm{p}=0.000)$

$19.39(\mathrm{p}=0.004)$ $34.98(\mathrm{p}=0.000)$

Increase in likelihood ratio $26.58(\mathrm{p}=0.000)$

$\mathrm{CI}=$ Confidence interval; $\mathrm{OR}=$ Odds ratio 
acteristics (parity, maternal awareness about vitamin A) contributed 26.58 (32.84\%), and household characteristics (religion) contributed 34.98 $(43.22 \%)$, indicating that, while maternal and child-related attributes constitute modest risks, religion constituted the single most important risk to subclinical vitamin A deficiency among children in Ethiopia.

The results of the comparison of the identified risk factors among Muslim and Christian children are presented in Table 4 . The proportion of Muslim children who had completed vaccination was significantly lower than the proportion of Christian children who had completed vaccination. The proportion of Muslim children belonging to large-family households, mothers with more births, illiterate mothers, and mothers with low levels of awareness of vitamin A were significantly $(\mathrm{p}<0.001)$ higher compared to children from Christian households.

\section{DISCUSSION}

The fact that vitamin A deficiency is strongly as- sociated with disease is well-substantiated. Studies have clearly shown that diarrhoeal disease affects vitamin A status by increasing loss of nutrients substantially (3). Similarly, intestinal parasites, such as Giardia, Ascaris, and hookworm, reduce the absorption of nutrients. Results of studies also indicate that respiratory-tract infections compromise the dietary absorption of vitamin A $(14,15)$. The substantial contribution of childhood illness to vitamin A deficiency is corroborated by findings of the present study. In addition, the importance of immunization in preventing childhood illness and vitamin A deficiency is highlighted by the findings of this study. The study also confirmed the fact that vitamin A supplementation is an efficient intervention to prevent and control vitamin A deficiency.

Parity is one of the demographic characteristics presumed to affect the nutritional status of mothers and children. Repeated and short-spaced deliveries are known to deplete nutrients, compromising the capacity of mothers to adequately nourish their children. The findings of the present study sup-

\begin{tabular}{|c|c|c|c|c|c|}
\hline \multirow{2}{*}{ Variable } & \multicolumn{2}{|c|}{ Christian } & \multicolumn{2}{|c|}{ Muslim } & \multirow{2}{*}{$\begin{array}{l}\text { Significance* } \\
\text { (p value) }\end{array}$} \\
\hline & No. & $\%$ & No. & $\%$ & \\
\hline \multicolumn{6}{|l|}{ Household size $(\mathrm{n}=965)$} \\
\hline$\leq 5$ (small) & 366 & 63.0 & 193 & 50.3 & \multirow[b]{2}{*}{$\mathrm{p}<0.001$} \\
\hline$\geq 6$ (large) & 215 & 37.0 & 191 & 49.7 & \\
\hline \multicolumn{6}{|l|}{ Literacy status of mothers $(n=966)$} \\
\hline Unable to read/write & 299 & 51.5 & 289 & 75.1 & \multirow[b]{2}{*}{$\mathrm{p}<0.001$} \\
\hline Literate & 282 & 48.5 & 96 & 24.9 & \\
\hline \multicolumn{6}{|l|}{ Parity $(\mathrm{n}=957)$} \\
\hline 2 and below & 271 & 46.6 & 136 & 35.3 & \\
\hline 3 and above & 310 & 53.4 & 249 & 64.7 & \\
\hline \multicolumn{6}{|l|}{ Knowledge about vitamin A $(\mathrm{n}=966)$} \\
\hline None of the aspects & 435 & 74.9 & 326 & 84.7 & \\
\hline At least one aspect & 146 & 25.1 & 59 & 15.3 & \\
\hline \multicolumn{6}{|l|}{ Vaccination $(\mathrm{n}=966)$} \\
\hline Complete & 333 & 54.3 & 165 & 42.9 & \multirow[b]{2}{*}{$\mathrm{p}<0.001$} \\
\hline Not at all/incomplete & 248 & 42.7 & 220 & 57.1 & \\
\hline \multicolumn{6}{|l|}{ Illness $(\mathrm{n}=966)$} \\
\hline Not ill over 15 days & 308 & 53.0 & 205 & 53.2 & \multirow[b]{2}{*}{ NS } \\
\hline Ill over 15 days & 273 & 47.0 & 180 & 46.8 & \\
\hline \multicolumn{6}{|l|}{ Vitamin A supplementation } \\
\hline Has taken at least once over the year & 233 & 40.1 & 166 & 43.1 & \multirow[b]{2}{*}{ NS } \\
\hline Has not taken at all & 348 & 59.9 & 219 & 56.9 & \\
\hline
\end{tabular}


port this assertion. Maternal education status and maternal knowledge about nutrition and specific nutrients are believed to play a substantial role on the nutritional status of children. Although maternal education categorized as 'illiterate' and 'literate' showed no association with subclinical vitamin A deficiency, knowledge of the mothers about vitamin A showed a strong association with subclinical vitamin $A$.

The findings of the study relating to the low contributions of child attributes, the modest contributions of maternal attributes, and the high contributions of household attributes (religion) to the variations in subclinical vitamin A deficiency suggest that factors appearing to be distantly related to vitamin A deficiency can constitute a major risk to vitamin A deficiency. The findings highlight the potential synergetic impact of interventions that simultaneously address the child, maternal and household-related risk factors.

The differences in nutritional status between the Muslim and the Christian households have been reported in other studies. For example, findings of a study on the nutritional status of mothers in Hadiya zone indicated that Muslim women were more malnourished compared to Christian women (16). Similarly, the national study conducted in 19801981 documented a significant difference in clinical vitamin A deficiency among Muslim and Christian children (4). Obviously, religion per se could not be implicated as a cause affecting vitamin A status in particular and nutritional status in general. Religion exerts impacts through its influence in socioeconomic status, education, health and nutritional practices. Therefore, the difference in vitamin A status between Muslim children and Christian children is obviously due to the difference in other immediate and underlying causes. Although it was not supported by statistical analysis, the national vitamin A survey of 1980-1981 implicated the large family size of Muslim households (as a result of having more wives) as a possible explanation for the increased prevalence of vitamin A deficiency among Muslim children. Although significant differences in household size and education levels of mothers between the Muslim and the Christian children were observed, the contributions of these attributes to the observed variation in subclinical vitamin A deficiency may not be substantial because family size and education levels of the mothers were not associated with subclinical vitamin A deficiency in this study. However, the significant variation in the vaccination status of the children, parity levels of the mothers, and awareness of vitamin A (variables identified as risk factors to vitamin A deficiency) can be implicated as some most likely factors contributing to the significant variations in clinical vitamin A deficiency between the Muslim and the Christian children. In-depth studies are needed to elucidate the reasons why Muslim children are more at risk

Lack of information on socioeconomic status and dietary consumption of vitamin A is one of the major limitations of the study (this information was not collected due to time and budget constraints). Information on socioeconomic status and dietary consumption would have provided more insights on the risk factors. Moreover, information on these attributes could have provided more explanation about the difference in the vitamin A status between the Muslim and the Christian children.

In conclusion, the study revealed that the Muslim children were more vulnerable to vitamin A deficiency underlining the need to further investigate the reasons. Vitamin A supplementation has shown a marked positive impact on vitamin A status and must, therefore, be strengthened and intensified. The study revealed pronounced negative impacts of disease and incompletion of vaccination calling for intensification of efforts relating to enhancing child health and vaccination. The risk associated with increased parity levels and lack of awareness of vitamin A is highlighted, urging for creation of strengthened awareness-promotion activities relating to family planning and the importance of vitamin A. The modest associations of maternal attributes and the strong association of household characteristics (religion) to subclinical vitamin A deficiency underlines the need to address these factors, along with child-related factors.

\section{ACKNOWLEDGEMENTS}

The authors thank the United Nations Children's Fund for the generous financial support and facilitation in the procurement of chemicals and reagents. The authors thank the staff of Family Health Department, Federal Ministry of Health, especially Dr. Tesfanesh Belay, Head of the Family Health Department and Sister Selamawit Negash whose personal efforts were instrumental for the success of the survey. They also thank district- and village-level authorities for their facilitations and also children and households who participated in the survey for their willingness to be involved in the study. The authors extend their thanks to many support staff at the Ethiopian Health and Nutrition Research In- 
stitute. Staff at public relations section, purchasing section, drivers, mechanics, and secretaries must receive their sincere thanks for their unstinted support. Finally, the authors appreciate and thank Mrs. Abebech Demissie for her high-standard data-management services.

\section{REFERENCES}

1. Mclaren DS, Shirajian E, Tchalian M, Khoury G. Xerophthalmia in Jordan. Am J Clin Nutr 1965;17:117-30.

2. Sommer A, Tarwotjo I, Hussaini G, Susanto D. Increased mortality in children with mild vitamin A deficiency. Lancet 1983;2:585-8.

3. Sommer A, West KP, Olson JA, Ross AC. Vitamin A deficiency: health survival and vision. New York, NY: Oxford University Press, 1996. 464 p.

4. Woldegebriel Z, Demeke T, West CE. Xerophthalmia in Ethiopia: a nationwide ophthalmologic, biochemical and anthropometric survey. Eur J Clin Nutr 1991;45:469-78.

5. Demeke T, Gebre H. Xerophthalmia: a review of hospital out-patient records. Ethiop Med J 1982;20:1520.

6. Demissie T, Haider J, Tibeb HN, Haile B. Impact evaluation of EPI-PLUS and WIBS approaches in controlling vitamin A deficiency in Tigray and Harari regions, Ethiopia. Ethiop J Health Dev 2000;14:303-10.

7. De Sole G, Belay Y, Zegeye B. Vitamin A deficiency in southern Ethiopia. Am J Clin Nutr 1987;45:780-4.

8. Haider J, Demissie T. Malnutrition and xerophthalmia in rural communities of Ethiopia. East African Med J 1999;76:590-3.
9. Haider J, Demisse T, G/Sillasie HM, Fufa H, Biratu IE. Vitamin A deficiency status in Tigray region, Ethiopia. Ethiopian J Health Dev 1999;13:87-91.

10. Demisse T, Haidar J, G/Sillasie H. Birratu E, Fuffa H. Vitamin A status in three weredas of Kembata, Alaba and Timbarro zone, SNNRP region. Ethiop J Health Dev 1998;12:225-9.

11. Haddad L, Ross J, Oshaug A, Torheim LE, Cogill B. $5^{\text {th }}$ report on the world nutrition situation, 2004: nutrition for improved development outcomes. Geneva: United Nations Standing Committee on Nutrition, 2004. $143 \mathrm{p}$.

12. Catignani GL, Bieri JG. Simultaneous determination of retinol and alpha-tocopherol in serum or plasma by liquid chromatography. Clin Chem 1983;29:708-12.

13. World Health Organization. Indicators for assessing vitamin A deficiency and their application in monitoring and evaluating intervention programmes. Geneva: World Health Organization, 1996. 66 p. (WHO/NUT/96.10).

14. Alvarez JO, Salazar-Lindo E, Kohatsu J, Miranda P, Stephensen CB. Urinary excretion of retinol in children with acute diarrhea. Am JClin Nutr 1995;61:12736.

15. Curtale F, Pokhrel RP, Tilden RL, Higashi G. Intestinal helminths and xerophthalmia in Nepal. A case-control study. J Trop Pediat 1995;41:334-7.

16. Demissie T, Mekonen Y, Haider J. Agroecological comparisons of levels and correlates of maternal malnutrition in Hadiya zone, SNNPR. Ethiop J Health Dev 2003;1:34-41. 